\title{
Fibrodysplasia Ossificans Progressiva: A Case Report
}

\author{
Sudeep Acharya, ${ }^{1}$ Sandhya Joshi, ${ }^{2}$ Rajib Chaulagain ${ }^{3}$ \\ ${ }^{1}$ Department of Oral and Maxillofacial Surgery, KIST Medical College and Teaching Hospital, Imadole, \\ Lalitpur, Nepal, ${ }^{2}$ Dental Surgeon, Maxillofacial Unit, National Academy of Medical Science, National Trauma \\ Center, Mahankal, Kathmandu, Nepal, ${ }^{3}$ Department of Oral Pathology, KIST Medical College and Teaching \\ Hospital, Imadole, Lalitpur, Nepal.
}

\begin{abstract}
Fibrodysplasia ossificans progressiva is a genetic disorder of the connective tissue differentiation characterized by congenital malformation of the big toes and progressive heterotopic ossification in the extra skeletal tissues like tendons, ligaments, fascia and skeletal muscles leading to permanent disability. The prevalence is one in two million people. During childhood, it may be asymptomatic but in later life, progressive stiffness of major joints renders movement of the individual impossible. Currently, there is no effective treatment for this debilitating disease. Here, we present a case of 27 year old male with clinical and radiological features of fibrodysplasia ossificans progressiva.

Keywords: Fibrodysplasia ossificans progressive; heterotopic ossification; myositis ossificans; myositis ossificans progressive.
\end{abstract}

\section{INTRODUCTION}

Fibrodysplasia ossificans progressiva (FOP) is a rare form of connective tissue disorder characterized by congenital malformation of great toes (hallux valgus) and progressive heterotopic ossifications. ${ }^{1}$ It has a prevalence of $1 / 2,000,000$ with no specific gender, ethnic or racial predisposition. ${ }^{1,2}$ The disease initially appears as episodic flare-ups which later progresses into heterotrophic ossification of skeletal muscles, tendons, ligaments, fascia and aponeuroses. Traumas, injections during the dental procedures and influenza-like illness have also been reported to induce the flare ups $s^{1,2}$ and subsequently leading to progressive physical immobility and decreased quality of life. ${ }^{3}$ Here, we report a case of fibrodysplasia ossificans progressiva in a young male.

\section{CASE REPORT}

A 27 year old male presented with a history of fall from bed and sustained trauma to his left arm followed by inability to move the extremity due to severe pain. He was asymptomatic till he was 10 years old, then he experienced repeated episodes of back pain and body ache accompanied by multiple painful soft tissue masses located in the back and trunk. These masses now have become hard and painless (Fig. 1A). He used to take pain killers during the acute phases of the disease. He gradually developed progressive deformity of the back and extremities. He was unable to move his neck, open mouth, and he had also developed restricted movements in all the levels of spine, shoulder girdle, elbow, hips and knees and had been bedridden from the past 5 years.

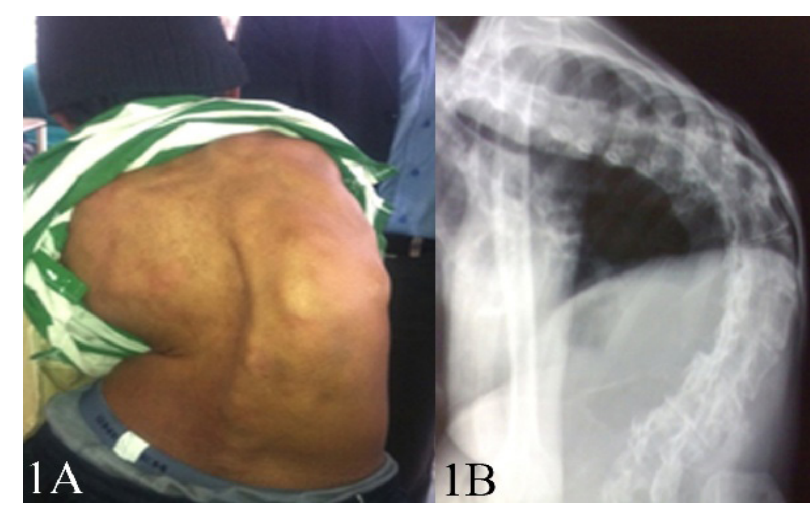

Figure 1A.Body deformity and extensive heterotopic ossification on the back of the patient.B. Lateral radiography of the spine showed kyphoscoliosis.

There was a rigid kyphoscoliosis involving dorsal and lumbar spine. The surface overlying the back and trunk showed multiple, painless, immobile, hard masses (Fig. 1B). The left arm showed painful movement at the distal shaft of humerus and major joints demonstrated stiff flexion contractures. The patient had hallux valgus with macrodactyly of bilateral great toes and thumbs with contracted $1^{\text {st }}$ web space (Fig. 2A and 2B).

The skeletal survey revealed a huge mandibular cyst on the right side, undisplaced fracture of the left humerus
DOI: $\underline{\mathrm{http}: / / \mathrm{dx} \text {.doi.org/10.3126/ }}$ jnhrc.v16i2.20319
Correspondence: Dr Sudeep Acharya, KIST Medical College, Imadole, Kathmandu, Nepal. Email: drsudeepacharya@gmail.com, Phone: +9779851147241. 
along with multiple ectopic exostoses on the anterior and posterior surfaces of the humerus (Fig. 3A). The lateral view $\mathrm{X}$-ray of spine showed large dorso-lumbar kyphoscoliosis with ankylosis and multiple ossifications in relation to soft tissues along the lateral border of chest. The feet X-rays revealed deformed, hypoplastic $1^{\text {st }}$ metatarsal with ankylosed metatarsophalangeal joint and interphalangeal joint. Hand X-ray showed hypoplastic $1^{\text {st }}$ metacarpal with ankylosed $1^{\text {st }}$ metacarpophalangeal joint.

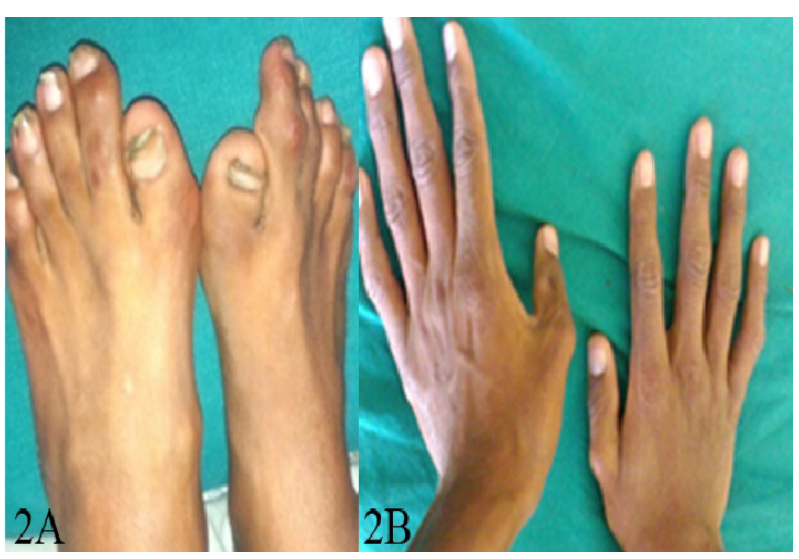

Figure 2A.Characteristics malformed great toes. B. Image of hand showing shortening of first phalanx of thumb.

The haematological and biochemical parameters were within normal range and other systemic examinations were unremarkable. The ultrasound of the abdomen revealed normal findings.

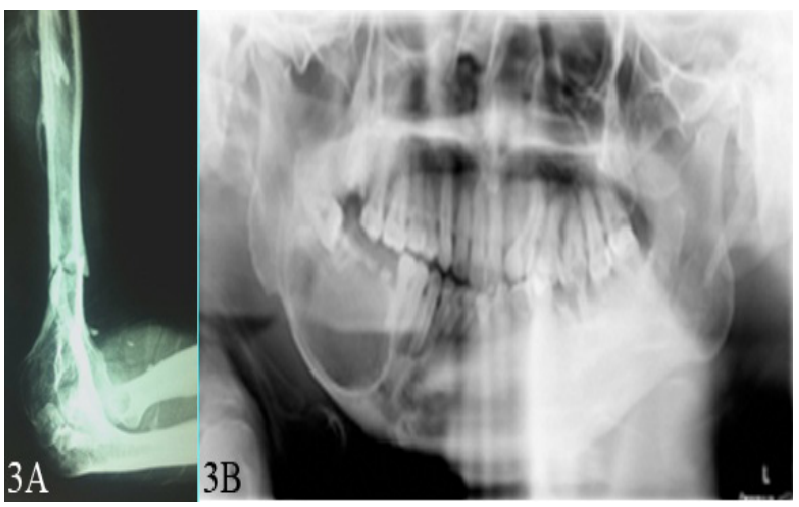

Figure 3A. Radiograph showing fracture of left humerus. B. OPG showing unilateral cystic involvement on the right side of the mandible.

Extraoral examination revealed significant facial asymmetry- elongated left side of face, rounded right side of face and reduced mouth opening. Multiple carious teeth were visible with the help of mouth mirror and cheek retractor; however, other areas could not be examined due to restricted mouth opening. Significant buccal cortical expansion extending from 45 tooth to the angle of the mandible was observed. The OPG revealed a unilocular radiolucency with a distinct sclerotic border extending from 45 to the angle of the mandible enclosing horizontally impacted 48 with ankylosis of right temporomandibular joint was also evident (Fig. $3 B)$.

The fracture of left humerus was managed conservatively by orthopaedic team. The ankylosis of the mandible and the cyst was left untreated owing to his medical condition.

\section{DISCUSSION}

In 1692, Guy Patin described the first case of progressive muscle ossification. ${ }^{4}$ Fibrodysplasia ossificans progressiva is an autosomal dominant disorder. ${ }^{1}$ Extensive work performed have identified a heterozygous mutation in the glycine serine domain of activin receptor $1 \mathrm{~A} /$ activinlike kinase 2 (ACVR1/ALK2), a BMP type 1 receptor leading to dysregulated BMP signaling. ${ }^{5}$ However, the molecular mechanism of the progressive heterotopic ossification is still unclear.

It usually occurs from birth up to the age of 16 years spontaneously of following trauma inducing "flare ups". 6,7 Abnormality of great toes (bilateral hallux valgus macrodactyly with hypoplasia of the phalanges) is the "pathognomic initial sign" which has been reported in $79-100 \%$ of patients. ${ }^{8}$ In our case, same features were present since birth and now he has developed complete stiffness of the toes due to joint surface tension and degenerative arthritis. The initial symptoms were painful soft tissue swellings over the affected muscle gradually leading to heterotopic ossification occurring in specific anatomic pattern. ${ }^{1,6}$ The disease was first seen in axial, cranial, proximal and dorsal regions and later on followed by appendicular, caudal, distal and ventral regions of body. ${ }^{9}$ The diaphragm, cardiac and smooth muscles, extraocular muscles and skin are not involved in FOP. ${ }^{2}$ Scoliosis is a common finding and is often the result of asymmetric heterotopic bones connecting the trunk and pelvis. ${ }^{1}$ Our case initially experienced painful lumps in the nape of neck and along the sides of the chest at around the age of 17 years which later on affected other extremities and ultimately ossified.

Progressive episodes of heterotopic ossification lead to ankylosis of all major joints rendering stiffness. Generally within the second decade of life, patients are confined to bed or wheelchair. ${ }^{1}$ Extensive involvement of muscles of chest wall and the spinal deformity leads to a restrictive lung disease and death may ensue due to pneumonia. ${ }^{1}$ Involvement of muscles of mastication 
Fibrodysplasia Ossificans Progressiva

results in feeding difficulties and malnutrition. Jaw fixation is a key feature in this disease ${ }^{10}$ and surgical attempts to restore mobility of the jaw have been unsuccessful. ${ }^{11}$ Our patient had not only stiff jaw but also had a huge mandibular cyst on the right side which has not been reported yet by any author. He has been on liquid diet for the last 5 years.

The diagnosis is mainly clinical and usually based on three major criteria; congenital malformation of great toes, progressive heterotopic ossification and progression of disease in well-defined anatomical pattern. ${ }^{3}$ Radiographs are normal in the early disease but $\mathrm{CT}$ scan and contrast enhanced CT/MRI can detect early ectopic calcifications. ${ }^{1}$ Laboratory tests are usually unremarkable except for the ESR which may increase during the "flare ups". ${ }^{4}$

There is no known effective medical treatment for FOP. ${ }^{3}$ Bisphosphonates has been studied for its inhibitory effect on bone mineralization. The results of studies utilizing intravenous administration of Etidronate and oral steroid suggest that these agents may provide some benefit. ${ }^{12}$ Few reports have been published on use of Isotretinoin (13-cis-retinoic Acid) which is believed to inhibit differentiation of mesenchymal tissue into cartilage and bone. ${ }^{11,13}$ Traumas (including operative), injections during the dental procedures and influenzalike illness have also been reported to induce the flare ups and subsequent progression of disease. ${ }^{1,2}$ This makes the operative management of spinal deformity, ankylotic release, mandibular cyst enucleation, fracture management very difficult. Moreover, restricted neck and jaw movement may make intubation difficult and diminished thoracic compliance may lead to other postoperative complications. Therefore, precautionary measures have to be implemented to minimize the risk of injury. ${ }^{1,3}$

\section{CONCLUSIONS}

Fibrodysplasia ossificans progressiva is an extremely rare disease accounting for 1 in 20 million populations. Early recognition is important for genetic counselling and minimizing trauma. Safety recommendations include limiting high risk activities, using protective headgear, installing safety measures in house surroundings and finally avoidance of any surgical interventions as far as feasible.

\section{REFERENCES}

1. Kaplan FS, Le Merrer M, Glaser DL, Pignolo RJ, Goldsby RE, Kitterman JA, et al. Fibrodysplasia ossificans progressiva. Best Pract Res Clin Rheumatol. 2008;22(1):191-205. [DOI]

2. Pignolo RJ, Shore EM, Kaplan FS. Fibrodysplasia ossificans progressiva: diagnosis, management, and therapeutic horizons. Pediatr Endocrinol Rev. 2013;10(0 2):437. [PMID]

3. Kaplan FS, Pignolo RJ, Shore EM. From mysteries to medicines: drug development for fibrodysplasia ossificans progressiva. Expert Opin Orphan Drugs. 2013;1(8):63749.[DOI]

4. Gonçalves AL, Masruha MR, Campos CCd, Delai PLR, Vilanova LCP. Fibrodysplasia ossificans progressiva: case report. Arquivos de neuro-psiquiatria. 2005;63(4):10903.[DOI]

5. Shore EM, Xu M, Feldman GJ, Fenstermacher DA, Cho T-J, Choi IH, et al. A recurrent mutation in the BMP type I receptor ACVR1 causes inherited and sporadic fibrodysplasia ossificans progressiva. Nat Genet. 2006;38(5):525-7.

6. Mahboubi S, Glaser DL, Shore EM, Kaplan FS, Fibrodysplasia ossificans progressiva. Pediatr Radiol. 2001;31(5):307-14.

7. Pignolo RJ, Bedford-Gay C, Liljesthröm M, DurbinJohnson BP, Shore EM, Rocke DM, Kaplan FS. The Natural History of Flare-Ups in Fibrodysplasia Ossificans Progressiva (FOP): A Comprehensive Global Assessment. J Bone Miner Res. 2016 Mar 1;31(3):650-6.[DOI]

8. Shaikh N, Arif F. Fibrodysplasia ossificans progressiva. J Pak Med Assoc. 2011;61(4):397-9.

9. Pignolo RJ, Shore EM, Kaplan FS. Fibrodysplasia ossificans progressiva: clinical and genetic aspects. Orphanet J Rare Dis. 2011;6(1):1. [DOI]

10. Marrannes J, Box I, Haspeslagh M, Gryspeerdt S. Jaw fixation as the key to diagnosis of fibrodysplasia ossificans progressiva. JBR BTR. 2006;89(4):195.[Full Text]

11. Crofford LJ, Brahim JS, Zasloff MA, Marini JC. Failure of surgery and isotretinoin to relieve jaw immobilization in fibrodysplasia ossificans progressiva: report of two cases. J Oral Maxillofac Surg. 1990;48(2):204-8.[DOI]

12. Al-Salmi I, Raniga S, Al Hadidi A. Fibrodysplasia Ossificans Progressiva-Radiological Findings: A Case Report. Oman Med J. 2014;29(5):368.[PMID][DOI]

13. Zasloff MA, Rocke DM, Crofford LJ, Hahn GV, Kaplan FS. Treatment of patients who have fibrodysplasia ossificans progressiva with isotretinoin. Clin Orthop Relat Res. 1998(346):121-9.[PMID] 